\title{
Editorial
}

Adrián LLerena and Heike Jahnke

\section{Gérard Siest Prize awarded to Alžběta Hlaváčková at the 9th Santorini Conference}

https://doi.org/10.1515/dmpt-2018-0035

The 9th Santorini Conference "Systems Medicine and Personalised Health and Therapy: The Odyssey from Hope to Practice" was held from September 30 until October 3, 2018 in Greece. Over the last 16 years, the "Santorini Conference" became one of the most important conferences on genetic predisposition to health, disease, response to drugs and the environment, attracting scientists from all over the world. In 2018, the conference attracted more participants than ever before: more than 160 registered participants from academia, industry and clinical medicine attended the conference. Special focus was given to cardio-metabolic diseases and cancer, and we are pleased to announce that the poster entitled "Changes in plasma metabolomic profile during acute myeloid leukemia treatment" was awarded the Gérard Siest Prize. We congratulate the winner of the Gérard Siest Prize, Alžběta Hlaváčková from the Department of Biochemistry, Institute of Hematology and Blood Transfusion, Prague, Czech Republic. For the first time, De Gruyter, publisher of the journal Drug Metabolism and Personalized Therapy (DMPT), sponsored the winner of the poster award in memory of Gérard Siest, former Editor-in-Chief of DMPT and Founder President of the European Society of Pharmacogenomics and Personalised Therapy (ESPT) in 2010.

In their research, Hlaváčková and her colleagues applied targeted metabolomic analysis to study the changes in plasma concentration of 19 selected intermediates of glycolysis, tricarboxylic acid cycle, and amino acid metabolisms during diagnosis, treatment, and remission in 23 patients with acute myeloid leukemia (AML). The same number of healthy controls were studied. A quantitative metabolomics profiling of plasma samples was provided by liquid chromatography-tandem mass spectrometry (LC-MS/ MS). The authors found significant differences in plasma concentration of 16 metabolites between all the AML patients and the healthy controls. Furthermore, 14 metabolites were significantly elevated in samples of AML patients at the time of diagnosis compared to healthy controls, nine metabolites were significantly elevated in samples of AML patients after treatment compared to healthy controls, and 11 metabolites were significantly elevated in samples of AML patients during diagnosis compared to the time of remission. In samples of AML patients before transplantation compared to healthy controls 4 metabolites were still significantly elevated. The authors conclude that the knowledge of changes in various intermediate concentrations of selected metabolic pathways during diagnosis, course, and treatment of AML could help understand he occurrence, progression, and prognosis of this serious disorder.

We congratulate Alžběta Hlaváčková and her colleagues for their outstanding poster and the award. Alzbeta Hlavackova won a 1-year free online subscription to $D M P T$ and a monetary prize.

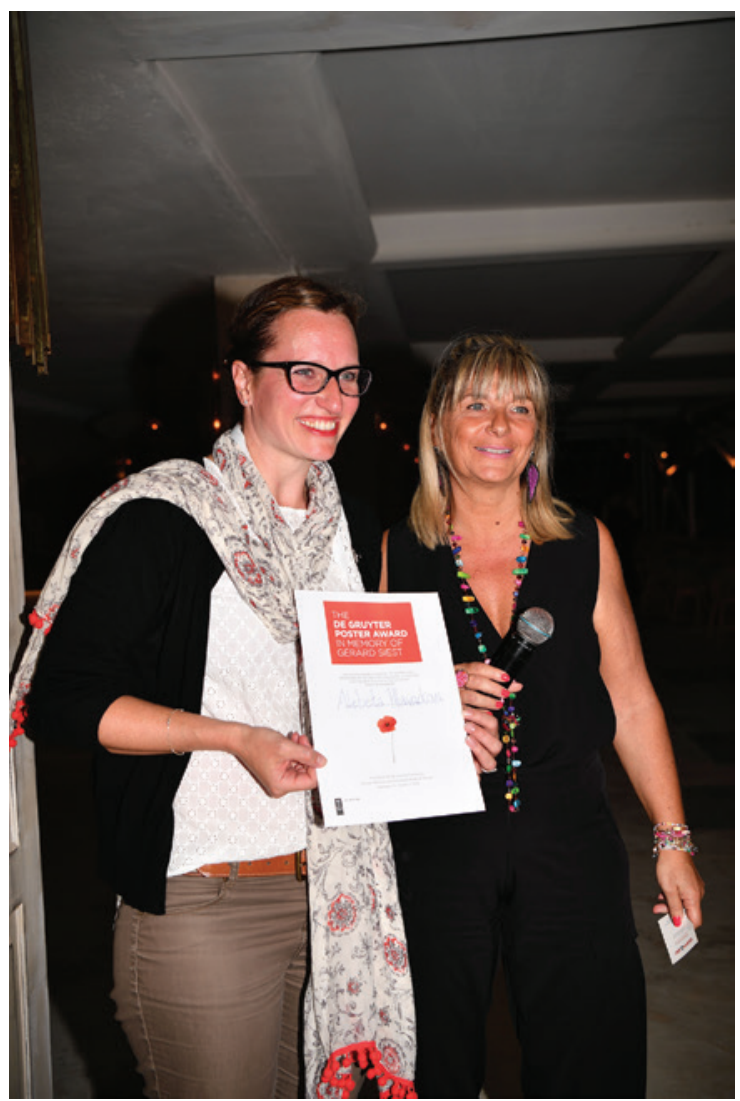

Prize winner Alžběta Hlaváčková and Brigitte Hiegel, Assistant Managing Editor DMPT, Nancy, France.

Adrián LLerena: Editor-in-Chief Drug Metabolism and Personalized Therapy, Badajoz, Spain

Heike Jahnke: Journal Editor Drug Metabolism and

Personalized Therapy, De Gruyter, Berlin, Germany,

E-mail: dmpt.editorial@degruyter.com 